\title{
RA?EGA
}

O ESPAÇO GEOGRÁFICO EM ANÁLISE

\section{ÁGUAS PASSADAS: SOCIEDADE E NATUREZA NO RIO DE JANEIRO OITOCENTISTA ${ }^{1}$}

\section{WATER AND SOCIETY-NATURE RELATIONSHIPS IN NINETEENTH-CENTURY RIO DE JANEIRO}

\author{
Diogo de Carvalho CABRAL ${ }^{2}$
}

\section{RESUMO}

O artigo discute as relações entre sociedade e natureza, na cidade do Rio de Janeiro, no século XIX. Nossa proposta metodológica é construir múltiplas narrativas que se desdobram e conectam a partir da observação das relações diretas e indiretas dos humanos com uma das substâncias mais importantes à sua reprodução biológica e social: a água. Assim construída, a trama entrelaça, de maneira complexa e contraditória, as propriedades, estruturas e processos do mundo biofísico, de um lado, e as ações humanas, nos domínios material, simbólico e ideológico. Em seu conjunto articulado, essas narrativas oferecemnos uma leitura da cidade e suas transformações. Esse tipo de método geohistoriográfico apresenta a vantagem de diluir as divisões apriorísticas, monolíticas e estáticas entre o social e o natural em favor de uma leitura dialética que parte do movimento e da transgressão contínuas entre aquelas fronteiras.

Palavras-chave: Metabolismo da água; Relações sociedade-natureza; Rio de Janeiro; século XIX; História Ambiental.

\footnotetext{
${ }^{1}$ Esta pesquisa recebeu o apoio da Coordenadoria de Aperfeiçoamento de Pessoal de Nível Superior (CAPES) na forma de uma bolsa de doutorado concedida ao autor. Meus agradecimentos a Letícia Ribeiro, Helena Drummond, Thais Reis, Marcus Vinicius Gomes, Renato Frias, Andre Avelar e Samira Moretto, além dos integrantes do Laboratório de História e Ecologia, coordenado por José Augusto Pádua no IFCS/UFRJ, pelos comentários críticos, sugestões de fontes e bibliografia, além das "consultorias" especializadas.

${ }^{2}$ Graduação em Geografia (UFRJ), Mestrado em História Social (PPGHIS/UFRJ) e Doutorando em Geografia (PPGG/UFRJ). Universidade Federal do Rio de Janeiro e University of British Columbia (Canadá). Email: dcabralufrj@gmail.com
} 


\section{ABSTRACT}

The paper discusses society-nature relationships in nineteenth-century Rio de Janeiro city. We propose a methodological framework based on the construction of multiple narratives that unfold and connect themselves from the observation of direct and indirect relations of humans with one of the most important substances to their biological and social reproduction: water. This plot weaves in a complex and contradictory way, in the one hand, the properties, structures, and processes of the biophysical world, and, on the other hand, human actions in the material, symbolic, and ideological domains. As a whole articulated, these narratives offer us a reading of the city and its transformations. This kind of geo-historiographical method has the advantage of diluting the a priori, monolithic and static divisions between the social and the natural in favor of a dialectical reading of the movement and nonstop transgression between those boundaries.

Key-words: Water metabolism; Society-nature relationships; Rio de Janeiro; Nineteenth-century; Environmental History.

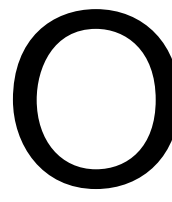

s geógrafos e os historiadores da cultura enfatizam que a água como qualquer outro elemento natural - nunca é "somente água" para os humanos. Estes sempre outorgam um significado à água. Água límpida, cristalina, água terapêutica, água-de-cheiro, água que rejuvenesce, água sagrada e água profana, água que traz o amor, água que nos purifica dos pecados: tudo isto é um elemento encontrado espontaneamente na natureza acrescido de sentido humano. Os geógrafos culturais investigam o mapa de significados atrelados à água e a forma como esses significados guiam a percepção e a ação dos indivíduos e dos grupos sociais diante dos lugares.

Embora a validade dessa abordagem seja inquestionável, acreditamos que perdemos algo quando menosprezamos a "água enquanto água", a água enquanto objeto social intransitivo, isto é, um objeto que "existe independentemente de seres humanos e construções sociais" (FOSTER, 2005, p.21). As “águas puras”, “águas límpidas” e “águas sagradas”, embora acrescidas de significado, continuam sendo água, uma coisa ordinária física dotada de certas propriedades e sendo capaz de estabelecer relações independentemente do modo como os humanos as concebem e valorizam. 
Mesmo o trabalho não abole o caráter "natural" dos objetos, na medida em que estes não se tornam imunes às forças e influências não-humanas às quais estavam anteriormente submetidos. A água "oferece-se" aos humanos, mas dentro de um determinado contexto biofísico que baliza, na relação dialética com os objetivos sociais e possibilidades técnicas, os parâmetros práticoconcretos de sua disponibilidade. Essas condições, no entanto, nunca param de se renovar, ainda que a água, ela mesma, nunca deixe de ser água. A água muda apenas para se manter a mesma. Diferentemente de uma maçã, que deixa de ser maçã quando consumida, ou uma árvore, que cessa de ser árvore quando transformada em madeira, a água sempre volta ao seu estado inicial, em algum ponto da cadeia metabólica (TVEDT, 2010). ${ }^{3}$ Há uma "vida natural" na água que subsiste e reage às tentativas humanas de apropriação e transformação, criando dialeticamente novas condições à sua objetivação.

Esta posição evita o perigo do reducionismo contido na noção de "produção social da natureza". Endossando uma visão excepcionalista dos humanos, os geógrafos vilipendiam ou simplesmente ignoram a dinâmica da natureza; dita hoje indissociável da ação humana, essa natureza acaba perdendo totalmente sua especificidade (HAESBAERT, 2007). Não é o caso, certamente, de negar as mediações fundamentais da linguagem, dos símbolos, dos valores morais, dos discursos especializados (notadamente o discurso científico), mas sim de reconhecer que o domínio natural tem características irredutíveis à cultura e às representações, embora internalize as relações dialéticas definidas por esses outros domínios (SWYNGEDOUW, 2001). É necessário considerar tanto a mediação da água pela sociedade quanto a mediação da sociedade pela água, uma dialética que não pode ser alcançada sem o pleno reconhecimento de que a água existe independentemente dos modos culturais de conhecê-la (TVEDT, 2010). Se não pudermos nos referir à água como coisa, permaneceremos "para sempre presos dentro de idéias, sem saída para o rés-do-chão do mundo" (PLUMWOOD, 2006, p.141). Os historiadores ambientais insistem na importância dessa materialidade

\footnotetext{
${ }^{3}$ Isso não quer dizer, evidentemente, que a água não possa solubilizar outras substâncias - ao ponto, inclusive, de se tornar inconsumível pelos humanos. Mas, mesmo assim, a água não deixou de ser água, embora o custo de sua limpeza possa ser economicamente proibitivo.
} 
independente dos humanos (ver WORSTER, 1991; WHITE, 1999; STROUD, 2003, entre outros). Evidentemente, as coisas da natureza carecem de significado em si mesmas e o que nos interessa, em última instância, são sempre os valores criados e corporificados nessas coisas pelos interesses e conflitos humanos. Ainda assim,
a natureza dificilmente é silenciosa. Não importa o que as pessoas façam, suas ações têm conseqüências reais sobre a natureza, da mesma forma que os eventos naturais têm conseqüências reais para as pessoas. Ao narrar essas conseqüências, inevitavelmente interpretamos seus significados de acordo com valores humanos - mas as conseqüências elas mesmas são tanto escolha da natureza quanto nossa. Nessa medida, a natureza é co-autora de nossas estórias (CRONON, 1992, p.1373).

Esse conceito de co-autoria é importante porque enfatiza que, embora a história ambiental esteja ancorada sobre uma base realista, ela - como qualquer outro ramo historiográfico - não é mimética, mas diegética (VEYNE, 1982). A história ambiental não reproduz a natureza, mas a dramatiza - na verdade, como qualquer romance. A linguagem narrativa tem uma lógica própria que nunca é suprimida, mas que é limitada pelos dados e dinâmicas naturais (CRONON, 1992). Seguir os enredos ou "itinerários" que perpassam a água leva-nos a múltiplos fenômenos e processos, em variadas escalas espaciais e temporais. A ecologia da água converte-se em um recurso epistemológico a partir do qual é possível "narrar muitas estórias interrelacionadas da cidade":

[...] a estória do seu povo e dos poderosos processos socioecológicos que produzem o urbano e seus espaços de privilégio e exclusão, de participação e marginalidade, de ratos e banqueiros, de doença de veiculação hídrica e especulação acerca do futuro e das opções da indústria da água, de reações e transformações químicas, físicas e biológicas, do ciclo hidrológico e do aquecimento global, do capital, das maquinações e estratégias dos construtores de barragens, de incorporadores do solo urbano, dos conhecimentos dos engenheiros, da passagem do rio para os reservatórios urbanos (SWYNGEDOUW, 2001, p.85). 
A construção de uma tal rede narrativa é uma maneira muito poderosa de conhecer os espaços humanos. Neste ensaio, tentaremos explorar essa forma de conhecimento ao examinarmos a cidade do Rio de Janeiro, no século XIX. O Rio oitocentista é especialmente interessante à abordagem políticoecológica; foi um lugar convulsionado por intensas transformações sociais e ecológicas que estiveram associadas, num primeiro momento, ao fim da situação colonial (abertura ao livre comércio internacional) e, posteriormente, à dissolução do escravismo e à transição para as relações capitalistas de produção. Não procedemos nenhuma pesquisa documental mais aprofundada, de modo que não adicionaremos nenhum novo evento à história conhecida desse centro urbano. Todos os eventos mobilizados já foram mais ou menos documentados e analisados na extensa historiografia existente. Pretendemos, tão-somente, articular alguns desses eventos de uma nova maneira, na tentativa de realçar conexões que possam nos oferecer uma outra leitura do século XIX carioca.

A luta dos habitantes da cidade do Rio de Janeiro pela água - mas também contra ela - sempre foi das mais árduas (ABREU, 1997). Fundada com propósitos militares de defesa do território, a cidade foi erguida em uma posição completamente desfavorável para a obtenção de água potável. O Rio tinha como função garantir o monopólio português sobre as riquezas coloniais de sua hinterlândia. Mas isto fazia com que a sua própria reprodução material ficasse ameaçada, pois o sítio natural não oferecia as duas coisas de que necessitava a cidade ao mesmo tempo: ou se tinha água para seus habitantes ou se tinha uma melhor posição para a visualização de ataques marítimos. Esse imperativo de defesa explica porque o Rio, diferentemente da esmagadora maioria das urbes baixo-modernas, não foi instalado próximo a uma grande fonte de água doce - algo que teve enormes conseqüências ao desenvolvimento posterior da cidade. Na várzea circundante ao morro do Castelo, atalaia e berço definitivo do Rio, os poços abertos não ofereciam mais 
do que uma água salobra (ABREU, 1992). Assim, o rio Carioca, que já servira para 0 abastecimento quando a cidade ainda se encontrava na praia entre os morros Cara de Cão e Pão de Açúcar, continuou a ser buscado para esta função.

Para a geopolítica portuguesa, o Rio existia muito mais como o nó de uma rede dendrítica que captava o excedente colonial e o enviava à metrópole do que como a base geográfica de um agrupamento humano. Não havia maiores compromissos com a cidade além daqueles indispensáveis à extração do excedente agrícola. Assim foi que a captação da água do rio Carioca e sua condução por meio de encanamentos até a cidade - uma obra clamada pela população desde o começo do século XVII - demoraria mais de um século para ser feita. O que certamente pesava mais na avaliação da Coroa era o fato de que a dependência em relação ao rio Carioca não era nada interessante em termos defensivos. O rio desaguava a aproximadamente três quilômetros de distância ao sul da cidade. Bastava que o inimigo ocupasse a atual praia do Flamengo para que o Rio fosse então conquistado. Era desejável, portanto, que se trouxesse a água para dentro do pequeno aglomerado urbano. Aparentemente, as invasões francesas de 1710-11 ajudaram as autoridades metropolitanas a visualizar o tamanho do prejuízo advindo da conquista da cidade por potências estrangeiras. Acelerada ou não por esse percalço, o fato é que, em 1723, finalmente, a obra de captação foi realizada e as águas do Carioca passaram a ser conduzidas até um reservatório situado no morro de Santo Antônio, alimentando o chafariz da Carioca, no atual Largo de mesmo nome (ABREU, 1992).

Até meados do século XIX, predominou, na cidade, o que Benchimol (1990, p. 65) chamou de "sistema colonial-escravista de distribuição de água". $\mathrm{O}$ abastecimento era realizado através de duas redes interconectadas. A primeira delas, encargo da Coroa e, posteriormente, do governo imperial, era a rede "técnica": a materialidade fixa composta pelos encanamentos que conduziam a água das altas nascentes até pontos de coleta dentro do espaço urbano (bicas e chafarizes, estes últimos os mais importantes em razão da 
maior vazão). ${ }^{4}$ A outra rede era movimentada pelos corpos humanos orquestrados pela instituição da escravidão: negros domésticos e de ganho que coletavam a água, nas bicas e nos chafarizes, e a transportavam em barris para os seus senhores ou a vendiam pelas ruas da cidade. Com o crescimento da demanda, até mesmo brancos pobres entraram neste ramo de serviço (KARASCH, 2000[1987]).

Até a chegada da Corte portuguesa ao Rio, todos os chafarizes estavam localizados na metade sul da cidade (FRIAS, 2010). As freguesias da Candelária (o que hoje se conhece como "Centro Histórico") e de Santa Rita (a atual Zona Portuária), onde de fato pulsava a vida econômica da cidade, não eram atendidas. Os moradores da Cidade Nova, do Valongo, da Gamboa e do Estuário de São Diogo não dispunham da água próxima e eram obrigados a se abastecer no chafariz da Praça do Carmo (atual Praça XV de Novembro) ou então em São Cristóvão, donde traziam a água em canoas (SILVA, 1965). Além desse descompasso, provavelmente pressionava por mudanças o temor em relação a possíveis sublevações escravas. Reinava na capital, se não um verdadeiro "terror negro", pelo menos um medo onipresente de rebeliões, um sentimento certamente alimentado pela memória ainda viva da revolta ocorrida no Haiti, na década anterior (OLIVEIRA LIMA apud MARTINS e ABREU, 2001, p.547). Os chafarizes eram lugares de espera e de imensa aglutinação de negros, sendo, portanto, lugar privilegiado para a formação e manutenção de redes sociais mais amplas. É possível que aumentar o número de pontos de coleta e, assim, diminuir a quantidade de cativos por chafariz, tenha constituído uma estratégia para evitar o contato social e as mobilizações.

Mas para que essa dispersão fosse possível, era necessário aumentar o volume de água à disposição das caixas d'água e, principalmente, captar rios mais próximos às áreas carentes situadas nas porções norte e oeste da cidade. Único grande manancial captado até então (além de alguns outros riachos na mesma bacia), o rio Carioca originava-se na serra de mesmo nome, cinco quilômetros a sudoeste da cidade, estendendo-se no sentido oeste-leste, com uma pequena inclinação norte. Embora muito distante da cidade, a grande

\footnotetext{
${ }^{4}$ Havia também chafarizes privativos, especialmente de religiosos, como o do Convento da Ajuda - o "chafariz das saracuras" -, transferido, em 1911, para a Praça General Osório, em Ipanema.
} 
altitude de seu nascedouro, na Serra da Carioca (acima da cota 600m) e, portanto, a energia potencial de suas águas, capacitava-o a ser encanado até muito longe. Mesmo assim, esse potencial não era infinito e os pontos de distribuição ficavam restritos às proximidades do morro do Desterro (Santa Tereza) e do morro de Santo Antônio. Para abastecer a porção oeste e norte da malha urbana, seria preciso utilizar os rios que desaguavam no Estuário de São Diogo. Destes, apenas o riacho Catumbi havia sido encanado e isto no ano de 1786. Logo depois de sua chegada ao Brasil, d. João VI empregou recursos para o encanamento do rio Maracanã. Mas como essa obra fosse demorar a ser concluída, resolveu-se construir, em 1809, um encanamento provisório para trazer as águas do rio Comprido, próximo à sua nascente, conectando-o à adutora do riacho Catumbi. Estas águas foram direcionadas ao Campo de Santana, onde se erigiu um chafariz também provisório, conhecido mais tarde como "chafariz das lavadeiras" (ABREU, 1992). Em 1817, finalmente, o encanamento do Maracanã foi finalizado e suas águas adicionadas ao sistema Catumbi-Comprido. Esses acréscimos facilitaram uma maior difusão dos chafarizes pelo tecido urbano, agora contemplando as freguesias de Santa Rita, Santana, Espírito Santo e São Cristóvão.

O crescimento da cidade e a complexificação de sua economia criaram duas demandas ecologicamente conflitantes ao maciço da Tijuca: água potável e biomassa (selvagem e cultivada). Todo serviço doméstico exigia a queima de madeira, assim como muitas manufaturas urbanas: padarias, torrefações de café, fundições, olarias, fábricas de papel, fábricas de vidro e porcelana, etc. Na década de 1880, o Rio de Janeiro consumia cerca de 270 mil toneladas anuais de lenha e 12 mil toneladas de carvão vegetal (DEAN, 1996, p.211). Ao findar o século XVIII, a Tijuca permanecia praticamente indevassada. Subindo o vale do rio Maracanã, em 1792, o secretário da embaixada britânica George Staunton relatou que tanto os cumes das montanhas quanto seus sopés encontravam-se guarnecidos de matas, enquanto as baixadas do vale eram cobertas por "árvores muitíssimo altas", de modo que "não se via um único pedaço de terra descoberto" (FRANÇA, 1999, p.225). A proximidade em relação à cidade faria com que essas florestas fossem rapidamente atacadas, 
principalmente a partir da segunda década da centúria, quando a estrada da Tijuca foi melhorada e o escoamento do carvão facilitado (VIANA, 1892). "Muitos fazendeiros se ocupam em tirar madeiras, ou ocasionalmente para suas construções, ou por especulação lucrosa", escreveu Carlos Augusto Taunay (2001[1839], p. 254), proprietário de um grande sítio na atual cascatinha Taunay, no final dos anos 1830. Some-se a isso a cafeicultura, que havia encontrado nas terras altas um ambiente bastante adequado, se não ideal, com bastante chuva e temperaturas amenas. Embora fosse um cultivo perene, os cafezais velhos não eram replantados, mas abandonados - com novas faixas de floresta sendo limpas para a manutenção da produção. Além disso, os plantadores ignoravam as vantagens do cultivo sombreado e desmatavam toda a floresta no processo de arroteamento (DEAN, 1996). Como resultado dessas práticas, já a partir da década de 1840, os anúncios de venda de terrenos que proclamavam a existência de "matos virgens" tornam-se progressivamente escassos (ABREU, 1992).

O desmatamento das encostas desequilibrava o regime hidrológico do maciço. A redução da capacidade do solo de absorver água produzia dois problemas gêmeos. Por um lado, ela aumentava a intensidade do escoamento superficial em direção aos canais de drenagem, elevando a freqüência dos transbordamentos e inundações. Por outro lado, ao escoarem superficialmente pelos solos, as águas das chuvas deixavam menos de si para trás de modo a recarregar o lençol freático e manter os rios correndo com uma vazão mais ou menos homogênea ao longo do ano. Assim, cada vez mais água era alocada nas planícies encharcadas dos rios, ao invés de ser armazenada nos reservatórios do sistema de abastecimento. Longe de serem um problema do tempo presente, as enchentes atormentam os habitantes do Rio desde que a cidade desceu para a planície. Os alagamentos e suas destruições já faziam parte da cultura citadina oitocentista, marcando e qualificando o tempo. (Em Dom Casmurro, as famílias de Bentinho e Capitu haviam se aproximado "desde aquela grande enchente".) O sítio em que se assentava o Rio antigo era basicamente um corredor de terras baixas ladeadas de montanhas e morros que se estendiam no sentido leste-oeste, na pequena península que ia do 
morro do Castelo ao mangal de São Diogo. É verdade que o caráter escarpado das vertentes montanhosas não engendrava apenas situações destrutivas: a força hidráulica foi importante para a indústria têxtil, com fábricas localizandose em várias partes do sopé do maciço da Tijuca - em Laranjeiras e no Jardim Botânico (ABREU, 2006). Mas essas unidades fabris situavam-se a alguma altitude, nos contrafortes da serra. Nas planícies propriamente ditas, muito baixas e niveladamente planas, as áreas que não eram permanentemente preenchidas de água (mangues, charcos e pequenas lagoas) o eram quando da ocorrência de chuvas mais intensas. A quebra abrupta do relevo favorecia o acúmulo das águas pluviais nos baixios que rodeavam as montanhas e morros. As valas, quase ao nível do mar, tinham pouca declividade. A vala principal da cidade antes da construção do Canal do Mangue (na atual rua Uruguaiana), estando quase sempre entulhada de lixo, não dava escoamento adequado às águas das chuvas; além disso, pelo fato do cano que levava água ao chafariz da Carioca atravessar essa vala, ele ficava à mercê da violência das correntes quando ocorriam temporais (ANRJ, Cx. 498, pct. 01). O desmatamento do mangue de São Diogo também guardava a sua parcela de culpa. Sem a vegetação para segurar o solo, o lodo era mobilizado e carreado para os estuários, obstaculizando o fluir das águas para o mar.

Como hoje, as enchentes transformavam as ruas em verdadeiros cursos d'água e os citadinos só podiam recorrer às canoas para se locomover. Muitas pessoas refugiavam-se nas igrejas que, nestas ocasiões, mantinham-se abertas dia e noite, com seus altares alumiados; os crentes aí elevavam preces aos céus e aos seus padroeiros, implorando o fim das chuvas. Os desabamentos de encostas eram constantes. O hoje desaparecido morro do Castelo tinha suas vertentes freqüentemente deslizadas e as casas assentadas sobre elas, destruídas. Na grande enchente de 1811, quando choveu sete dias seguidos, as encostas no nordeste do morro desabaram, provocando a destruição da maioria das casas do antigo Beco do Cotovelo (no que são hoje a Avenida Erasmo Braga e trecho final da Avenida Presidente Antônio Carlos). Não por acaso, datam desta época as primeiras reações para o arrasamento do morro do Castelo (IHGB, MP 1, Gav. 3, n. 12.). 
Um dos meios que os cariocas sempre utilizaram para vencer a água foi afogá-la na terra. A história dos inúmeros aterros que ajudaram a produzir 0 espaço urbano daria assunto para muitos volumes. O rearranjo físico do sítio foi viabilizado por uma série de relações sociais que, muitas vezes, passam despercebidas na narração épica da "luta contra os pântanos". Essa luta não era "do Homem", mas apenas de alguns homens. Havia aqueles para os quais o pântano não precisava ser combatido e eliminado, mas, pelo contrário, devia ser conservado - e, claro, deixado aberto ao uso comum. Pescadores, catadores de mariscos, cortadores de lenha, fabricantes de cal, curtidores de couro: todos eles perderam muito quando o mangal de São Diogo desapareceu, no último quartel do século (MILLER, 2003). O Estado atuava direta e indiretamente nos aterros. Para poupar dinheiro, ele empregava, por vezes, os réprobos da Casa de Correição. Além disso, a "conquista" dos terrenos brejosos foi incentivada através de isenções fiscais àqueles que entulhassem as áreas encharcadas. Esses "conquistadores" davam emprego a carroceiros que se ocupavam em transportar os materiais para despejar nos mangues, charcos e brejos. Grande parte desse material era constituída pelos próprios resíduos sólidos da cidade (ABREU, 1997).

Tão ou mais preocupante que o excesso de água era a escassez de água. A cidade em expansão exigia cada vez mais água potável. De 100 mil habitantes em 1822, o Rio passa a ter 135 mil em 1840, 205 mil em 1849 e 228 mil em 1872 (BENCHIMOL, 1990, p.25; ABREU, 1992, p.66). Essa população talvez não pudesse ser abastecida somente pelos rios que drenam o maciço da Tijuca e discussões foram travadas em torno da necessidade ou não de se buscar água fora do território municipal. Alguns engenheiros e técnicos defendiam a plena suficiência dos mananciais da Tijuca. Em 1873, Joaquim José de Souza Imenes, José Marcellino Pereira de Moraes e Raphael Archanjo Galvão Filho, empresários interessados em investir na infraestrutura da água, apresentaram à câmara legislativa uma proposta de reestruturação do sistema de abastecimento de água. Eles asseguravam que os rios do Corcovado, do Andaraí Grande e do Jardim Botânico forneciam 40 milhões de litros diários e, com captações adicionais, poderiam chegar a 85 milhões. Este volume, 
considerando uma população de 250 mil pessoas, seria suficiente para um fornecimento de 200 litros diários por cabeça, obtendo-se ainda uma reserva de substanciais 35 milhões de litros. O maior problema, segundo eles, era o desperdício ocasionado pelos "grandes defeitos organicos no systema geral de abastecimento": as caixas de recepção e distribuição tinham uma capacidade muito pequena, os encanamentos tinham um diâmetro reduzido, estavam enferrujados e entupidos por detritos, além de outros problemas técnicos que contribuíam para um desperdício de quase 30 milhões de litros (IMENES et alli., 1873). O pensamento dominante, no entanto, era de que seria preciso expandir os tentáculos de captação para além dos limites municipais. Em 1874, um "Projeto de abastecimento d'água para a cidade do Rio de Janeiro", organizado pelos engenheiros Jerônimo Rodrigues de Moraes Jardim (Inspetor de Obras Públicas), e Luís Francisco Monteiro de Barros, alegava que os mananciais do maciço da Tijuca contribuíam com apenas 15 milhões de litros. Além disso, apregoavam que o custo das reformas do sistema seria proibitivo, sendo mais interessante a utilização dos mananciais da Serra do Tinguá, $53 \mathrm{~km}$ ao norte da cidade (JARDIM e BARROS, 1874). Esta expansão acabou se concretizando no final dos anos 1870, com a construção do sistema que captava as águas do rio São Pedro e, posteriormente, também dos rios D’ouro e Tinguá.

É difícil precisar até que ponto os interesses capitalistas influenciaram esse desfecho para a controvérsia sobre a insuficiência da vazão dos rios do maciço da Tijuca. Há, contudo, dois fatos sugestivos. O primeiro é que havia potencial de lucro no negócio da água, pois vários grupos empresariais assediavam o governo para que concedesse a prestação do serviço, incluindo parcelas do capital nacional e do capital estrangeiro (MARQUES, 1995). Essa lucratividade estava baseada na substituição do fornecimento público e gratuito (nos chafarizes e bicas) para o fornecimento mercantil e doméstico. Em 1873, havia 711 torneiras abertas ao uso público e apenas $21 \%$ das residências da cidade tinham água encanada (IHGB, Arquivo, 15, 3, 23). O imperador era resistente à idéia de vender a água aos pobres ao invés de dá-la, gratuitamente. No final das contas, prevaleceu a noção de que o abastecimento 
de água constituía um serviço fundamental e que devia, portanto, ser administrado pelo Estado - diferentemente da iluminação, dos esgotos e dos transportes, que foram entregues a companhias privadas. A construção do sistema, contudo, precisou ser licitada e sob a garantia de juros para o capital investido. O segundo fato sugestivo é que, poucos anos depois de posto em funcionamento o novo sistema de captação (1880), a cidade voltava a enfrentar novas secas (BENCHIMOL, 1990), indicando que a solução do Tinguá não foi a panacéia que se esperava.

Ao longo de todo o século XIX, a chegada do verão - a temida "estação calmosa" - sempre trazia sofrimento. A Polícia, pelo menos no começo do século, sob a direção do intendente Paulo Fernandes Vianna, procurava amenizar esse sofrimento distribuindo água gratuitamente às áreas que ficavam mais distantes dos chafarizes (ANRJ, cód. 323, vol.4, cód. 327, vol.1). Houve secas mais críticas em 1824, 1829, 1833, 1843, 1861 e 1868, com o aumento progressivo da sua severidade. As três últimas adquiriram contornos especialmente dramáticos. De acordo com Abreu (1992, p. 76), "a seca de 1843 pode ser considerada como um marco divisório extremamente importante da história da cidade do Rio de Janeiro". A falta de água foi tão intensa e prolongada que se chegou ao extremo de procurar socorro nos navios que ancoravam na baía de Guanabara. Esgotados os tanques dessas embarcações, organizou-se uma frota de faluas para o transporte de água apanhada em Jurujuba e até mesmo no rio Macacu.

Nesse ano de 1843, o governo imperial instituiu comissão especial para sugerir medidas que pudessem resguardar, de forma definitiva, a cidade contra esse tipo de calamidade. Reconheceu-se, então, o imperativo de se proteger as florestas que cobriam os mananciais da Tijuca. Embora essa preocupação já existisse desde 1818 - quando d. João mandou "coutar" os terrenos dos altos das serras que cercavam as nascentes - a solução agora aventada era mais radical: admitiu-se a necessidade de se desapropriar os terrenos que margeavam os rios. Seriam precisos, porém, mais 12 anos até que essas desapropriações começassem a ser feitas. Esta delicada operação ficou sob os auspícios do ministro Luiz Pedreira do Couto Ferraz, o Visconde do Bom 
Retiro, personagem poderoso e ligado a um círculo de intelectuais engajados na discussão ambiental (PÁDUA, 2004). Além disso, iniciou-se o reflorestamento dessas terras. A plantação de cerca de 90 mil mudas de árvores, contudo, não foi tão importante quanto a regeneração natural. Ao ser deixada em seu livre curso, a sucessão ecológica deu origem ao que hoje conhecemos como a Floresta da Tijuca.

Evidentemente, essa iniciativa não poderia dar frutos no curto prazo. Embora seja muito difícil estabelecer relações causais nesse domínio, o fato é que a devastação florestal havia coincidido com uma significativa mudança no clima urbano. Desde o final do século XVIII, a cidade vinha se tornando mais quente e seca. No qüinqüênio 1781-85, a média de temperatura foi de $22,45^{\circ}$ C. Setenta anos depois, no qüinqüênio 1851-55, a temperatura média já havia atingido o nível atual, chegando a $24,24^{\circ} \mathrm{C}$. Considerando esses mesmos dois períodos, a média pluviométrica diminuiu 18,5\%, passando de $1.329 \mathrm{~mm}$ para 1.083mm (MORALES DE LOS RIOS FILHO, 2000[1946], p. 55-57). Uma estiagem mais aguda, no final dos anos 1860, jogou a cidade do Rio em uma nova e violentíssima seca. Como fenômeno único no longo período compreendido entre 1851 e 1990, o volume de precipitação caiu, por dois anos seguidos, abaixo do nível de 800mm, em 1868 e 1869 (Brandão, 1992, p. 172). Essa estiagem prolongada foi devastadora para o sistema de abastecimento. $O$ engenheiro André Rebouças escreveu em agosto de 1870: "A seca atingiu um ponto desconhecido desde 1847 que habito o Rio de Janeiro" (apud BENCHIMOL, 1990, p.68). Junto às torneiras das esquinas e dos chafarizes, as pessoas mais pobres acotovelavam-se durante horas para poder encher uma moringa ou, quando muito, uma pequena lata, o suficiente apenas para iludir a sede ou cozinhar a alimentação do dia.

É dentro desde quadro de alteração ambiental que devemos situar o reflorestamento do maciço da Tijuca, iniciado no terceiro quartel do século. Heynemann (1995) critica as interpretações materialistas que descrevem o reflorestamento como um produto das seguidas crises de abastecimento de água. Do ponto de vista da história cultural, essa autora chama nossa atenção para as motivações simbólicas que estavam envolvidas no apelo ao 
reflorestamento; notadamente, no âmbito do processo de construção e legitimação do Estado Imperial, o ideal de uma sociedade "civilizada" e a busca de uma ruptura com o "bárbaro" passado colonial.

Ainda que tenhamos que reconhecer que o domínio das representações tem uma dinâmica relativamente autônoma, deve-se lembrar que ele nunca está completamente desvinculado das questões do mundo material. Embora seja inevitável que os atores sociais elaborem simbólica e discursivamente os diversos problemas que surgem em seu trato objetivo do universo biofísico, essas elaborações nunca fundam sozinhas aqueles problemas (DRUMMOND, 2003). Muitas das representações que deram suporte ao projeto do reflorestamento dialogavam com transformações socioecológicas muito concretas, algo que é reconhecido por Heynemann: "Parece claro que esse discurso [da necessidade do reflorestamento] havia se intensificado na proporção da destruição das matas e do crescimento da capital, com o agravamento das condições de vida" (HEYNEMANN, 1995, p. 162). Mas Heynemann não explora essa destruição e essas condições de vida. $O$ entendimento histórico do projeto de reflorestamento passa pelo exame da interação entre as necessidades concretas da cidade e as motivações políticointelectuais dos seus idealizadores. No apoio ao projeto figuravam personagens que, de um lado, representavam os valores mais amplos das associações científicas e culturais da elite imperial - o Imperial Instituto Fluminense de Agricultura, a Sociedade Auxiliadora da Indústria Nacional, o Instituto Histórico e Geográfico Brasileiro - e que, de outro lado, constituíam uma tradição intelectual de crítica à degradação florestal. A decisão do Visconde do Bom Retiro, então Ministro do Império, de iniciar o processo de reflorestamento foi, de fato, bastante inspirada no ideário desse grupo intelectual. Mas o ministro, por mais influente que fosse, não teria conseguido angariar apoio para a epopéia do reflorestamento - a "viva imagem da loucura humana", nas palavras de José de Alencar - se não houvesse a falta de água a acossar a capital. Sem a presença desse problema concreto, é improvável que - Visconde do Bom Retiro tivesse encontrado argumentos políticos suficientemente fortes para iniciar uma obra cujos resultados apareceriam 
apenas décadas mais tarde (PÁDUA, 2004).

Outro fenômeno importante para entendermos o reflorestamento da Tijuca é uma emergente "sensibilidade idílica" dos citadinos ricos. Já havia, desde o início do século, um movimento de evasão das camadas sociais mais abastadas do centro em direção aos arrabaldes da cidade. Tanto São Cristóvão, a oeste, quanto a Glória, ao sul, ainda eram revestidos de matas, no início do século (LUCCOCK, 1975[1820]). A valorização da Tijuca era mais um passo nesse processo de aristocratização das periferias florestais. A nata da elite imperial - condes, viscondes, barões, ministros, embaixadores - fixou residência na Tijuca ou lá adquiriu "residências de veraneio" (HEYNEMANN, 1995). Mas o "retiro arborizado nas montanhas" (DEAN, 1996, p.239) era apenas um aspecto nessa debandada aristocrática. Endêmica desde 1850, a febre amarela havia transformado o centro da cidade em um lugar onde os ricos não queriam estar. No final dos anos 1860, fortes epidemias de febre coincidiram com as secas violentas já mencionadas para promover uma vertiginosa escalada da mortalidade: de três óbitos em 1868 e 272 no ano seguinte, passou-se a 1.118 vítimas em 1870 (BENCHIMOL, 1990).

A questão da febre amarela é muitas vezes tratada pelos estudiosos da história da cidade exclusivamente a partir da análise do pensamento médico e científico da época. Na Geografia Histórica brasileira, o primeiro estudo que tratou desse tema mais profundamente foi o de Damasceno (1993), no qual se problematiza a relação entre a famosa "teoria dos miasmas" e as transformações urbanas. ${ }^{5}$ A autora examina a genealogia da teoria, o contexto institucional da profissão médica no Rio de Janeiro oitocentista, a posterior apropriação e utilização da teoria pelos engenheiros no começo do século $X X$ entre outros temas. Em nenhum momento, porém, ela analisa a dinâmica epidemiológica da febre amarela. Em sua narrativa - e, sejamos justos, não apenas na dela, mas na de quase todos os que se dedicaram ao tema - a doença aparece quase como um desígnio divino, ou seja, algo que não é resultado de uma construção material. Nesse tipo de relato, a febre amarela

\footnotetext{
${ }^{5}$ Essa teoria do século XVIII identificava a origem de muitas doenças nessas "emanações pútridas" que recebiam o nome de miasmas. Tais emanações teriam múltiplas origens, mas as duas principais seriam a matéria orgânica em decomposição e as águas estagnadas.
} 
pertence ao domínio do não-factual, ou seja, trata-se de uma "historicidade da qual não temos consciência como tal” (VEYNE, 1982, p.19). Em uma abordagem totalizante, todavia, não é possível que um fato venha "do nada", "de fora" da realidade estudada. As representações científicas e ideológicas da febre amarela, como historicidades, só podem ser compreendidas na interação com outras historicidades, incluindo a evolução de microorganismos, de mosquitos, de paisagens. Ora, deste ponto de vista, percebemos que uma parte importante da explicação do sucesso da teoria miasmática é sua parcial e involuntária conformação ao complexo patogênico da febre amarela - mas também da malária, doença endêmica na cidade desde pelo menos o final do século XVIII (KARASCH, 2000[1987]) -, apontando um nexo causal com muitas formas de água parada. De fato, o que aproximava a teoria infeccionista dos miasmas da real etiologia da doença era sua grande ênfase no espaço, nas condições ambientais localizadas. ${ }^{6}$

Antes de 1849, a febre amarela havia aparecido esporadicamente, mas não assumira dimensão epidêmica (KARASCH, 2000[1987]). A primeira e talvez mais terrível dos eventos epidêmicos aconteceu entre dezembro de 1849 e março do ano seguinte. A doença atingiu mais de 90 mil dos 166 mil habitantes, fazendo 4.160 vítimas fatais - isto sem contar as mortes em domicílio que não chegavam ao conhecimento das enfermarias e hospitais. $^{7}$ Diferentemente dos pequenos surtos que tinham ocorrido antes - que, em sua esmagadora maioria, vitimaram os segmentos sociais mais pobres -, a epidemia de 1849-50 fez muitas vítimas fatais entre a elite residente na área central, chegando mesmo ao seu mais alto escalão, a própria família imperial, ao matar um filho de d. Pedro II (CHALHOUB, 1996). Este fato explica muito do excepcional assombro e da enérgica movimentação da classe dirigente, ainda que ela fosse muito mais "intelectual" do que prática.

A historicidade da febre amarela "tem que ver com os tempos inerentes às sociedades humanas e com os ciclos próprios à organização de outros

\footnotetext{
${ }^{6}$ É verdade que a teoria dos miasmas não era a única vertente explicativa da febre. Ela rivalizava ferozmente com a teoria do contágio. Foi a primeira, contudo, que forneceu o "arcabouço ideológico básico às reformas urbanas realizadas em várias cidades ocidentais na segunda metade do século XIX e primeiras décadas do século XX" (CHALHOUB, 1996, p.65).

${ }^{7}$ Conforme discutido por Chalhoub (1996, p.61 e notas de fim), algumas estimativas chegavam às cifras de 10,12 ou mesmo 15 mil vítimas fatais.
} 
seres, macro ou microscópicos" (BENCHIMOL, 1994, p.121). Epidemiologicamente, a febre amarela é uma zoonose, isto é, uma doença que pode ser transmitida de animais vertebrados aos humanos. Tanto o vírus causador quanto o principal vetor de transmissão são provavelmente originários da África. O mosquito Aedes aegypti, famoso em nossos dias por espalhar a dengue, é uma espécie que se adaptou aos ambientes domésticos e peri-domésticos dos humanos, por volta de 200 a.C., provavelmente em resposta à criação de um clima mais seco na África austral. Sua difusão foi facilitada pelas rotas de comércio transaarianas, aproximadamente a partir de 700 d.C. (BARRETT e HIGGS, 2007).

A migração da febre amarela para o Novo Mundo foi uma conseqüência importante da escravidão moderna e do mercado atlântico de escravos. Quando se fala na "produção social dos cativos"8, não se pode esquecer do complexo epidemiológico que também era (re)produzido e enviado à América. O mosquito e o vírus - no corpo de pessoas doentes - foram trazidos pelos navios negreiros e se instalaram, em primeiro lugar, nas cidades portuárias brasileiras. A fêmea do $A$. egypti faz sua oviposição em depósitos artificiais de água. Os ovos são postos alguns milímetros acima da linha da água, fixandose à parede do recipiente, onde resistem à dessecação. Alimentando-se de sangue, os mosquitos adultos alastram a infecção picando humanos doentes e depois picando outros humanos.

Restrito, em um primeiro momento, ao espaço urbano, o vírus da febre amarela adaptou-se a um ciclo silvestre. Na América do Sul de hoje em dia, a maior parte dos casos da enfermidade é registrada em áreas de exploração florestal. Cidade pré-industrial virtualmente cercada de florestas, o Rio possuía um intenso comércio madeireiro com sua hinterlândia imediata (Brown, 1986). Roceiros pobres das matas interiores do Recôncavo da Guanabara usavam canoas e lanchas para levar suas madeiras às praias da cidade, principalmente a de d. Manuel (atual rua de mesmo nome) (ANRJ, cód. 323, vol.1). Esta relação comercial regular pode ter levado às áreas florestais indivíduos doentes

\footnotetext{
${ }^{8}$ Ou seja, a apropriação violenta de todas as horas-trabalho gastas pelas comunidades humanas na manutenção dos indivíduos até o momento em que se tornavam prisioneiros (FRAGOSO e FLORENTINO, 2001).
} 
que iniciaram novo ciclo da febre amarela. Esses indivíduos eram picados por mosquitos da família dos Haemagogus, os quais permaneciam infectados por toda a sua vida. Além disso, macacos também podiam ser infectados e sabemos hoje que todas as espécies encontradas no Brasil são sensíveis à doença. Os Haemagogus são mosquitos hematófagos de atividade diurna que habitam as copas das árvores, exatamente onde espécies como o macacoprego vão buscar frutas, sementes, insetos e pequenos vertebrados para se alimentar. Embora os macacos não sejam reservatórios do vírus - porque morrem ou adquirem imunidade -, eles são dispersores importantes (HERVÉ et alli., 1986). É possível que essa adaptação tenha ocorrido antes da primeira grande epidemia carioca. "A febre amarela já se acha às suas portas [do Rio de Janeiro], e se ela entrar seus estragos serão tremendamente desoladores", vaticinava o comerciante inglês John Luccock (1975[1820], p. 90), em 1808. Pouco mais de três décadas depois, o vaticínio concretizava-se. Houve surtos anuais contínuos de febre amarela entre 1850 e 1902, excetuando-se apenas os anos 1865-67, vitimando mais de 58 mil pessoas (FIGUEIREDO e FONSECA, 2005, p.389).

Uma característica marcante da febre amarela é que ela atacava muito mais a população branca - e, especialmente, imigrante - do que a população negra. Isto não se devia a qualquer imunidade geneticamente herdada, mas ao fato de que os negros nascidos em algumas regiões da África tinham podido usufruir, desde crianças, do contato com a doença. Quando a febre amarela ataca os recém-chegados a uma determinada população humana (seja por nascimento, seja por migração), ela os mata ou os adoenta de maneira muito leve e, neste caso, dá a eles imunidade parcial ao próximo ataque (WATTS, 2001). As crianças normalmente só sofrem sintomas fracos e as suas possibilidades de sobrevivência são grandes. Assim, são os migrantes adultos são os que correm mais riscos, sobretudo os homens (MCNEILL, 1999). O fato de os brasileiros natos livres terem apresentado, no surto epidêmico de 184950, uma taxa de infecção semelhante aos escravos nascidos na África conforme estatística para a freguesia do Engenho Velho (KARASCH, 2000[1987], p.223) - reforça a hipótese de que a febre amarela ocorria 
esporadicamente havia já algumas décadas. Nesse primeiro surto, os negros adultos nascidos em solo brasileiro provavelmente tinham a mesma susceptibilidade à febre que os imigrantes brancos. Com o passar do tempo, contudo, todos os nascidos no Brasil, fossem eles de cor ou não, passaram a exibir muito maior resistência à doença do que os estrangeiros que chegavam ao país.

"Essa característica biológica ou natural da febre amarela", escreveu o historiador social Chalhoub (1996, p.71), "nunca deixou de acarretar conseqüências políticas e ideológicas importantes" no Rio da segunda metade do século XIX. Com este reconhecimento fundamental, Chalhoub abre caminho para uma das mais instigantes interpretações socionaturais sobre 0 lugar/período que é objeto do presente ensaio. Ele consegue captar a dialética entre a ecologia da febre amarela e a complexa conjuntura histórica relacionada à crise do escravismo e à ideologia racial. As propriedades biológicas da doença constituíam o campo para a imposição da escolha ${ }^{9}$, isto é, elas constituíam o universo do possível biofísico da ação política. A diferença na taxa de incidência da febre entre brancos e negros foi decisiva na definição das prioridades das políticas governamentais de saúde pública. A febre amarela não era a única e nem a mais mórbida doença que assolava o Rio de Janeiro de então. Entre 1870 e 1880, por exemplo, enquanto ela matou 14.541 pessoas, a tuberculose - que não mereceu nenhuma política pública mais sistemática - matou 20.916 (FRITSCH apud MARQUES, 1995, p.59). O que explica essa diferença na atenção das autoridades?

A febre amarela, flagelo dos imigrantes que, esperava-se, ocupariam o lugar dos negros nas lavouras do Sudeste cafeeiro, tornou-se o centro dos esforços de médicos e autoridades. Enquanto isso, os doutores praticamente ignoravam, por exemplo, uma doença como a tuberculose, que eles próprios consideravam especialmente grave entre a população negra do Rio. A intervenção dos higienistas nas políticas públicas parecia obedecer ao mal confessado objetivo de tornar o ambiente urbano salubre para um determinado setor da população (CHALHOUB, 1996, pp.8-9).

\footnotetext{
${ }^{9}$ Esta é uma expressão de Donna Haraway para se referir à natureza (apud PLUMWOOD, 2006, p.144).
} 
O que precisa ser retido aqui é que a atuação concreta das propriedades biológicas da febre amarela - e, por extensão, da água - foi pressuposto básico de uma excelente história "social". Haverá os que argumentem que o que Chalhoub mostra é exatamente o peso das vicissitudes históricas sobre a percepção da doença e, portanto, a "independência do pensamento e da ação humanas": enquanto, na década de 1850 , as preocupações com a febre amarela foram atenuadas pelo fato de ela acometer principalmente os imigrantes e estrangeiros de passagem pela Corte (e não os preciosos escravos), esse mesmo fato, vinte anos mais tarde, faria com que a febre fosse alçada ao posto de maior problema de saúde pública da cidade (e do país). Essa mudança refletia o contexto mais acelerado de dissolução do sistema escravista (a Lei do Ventre Livre fora editada em 1871) e a conseqüente necessidade dos cafeicultores brasileiros de apostar na importação maciça de mão-de-obra européia. Mas esse tipo de argumento - que, em sua forma geral, baseia-se na conhecida idéia de que as condições naturais permanecem "quase sempre as mesmas", enquanto a sociedade, ela sim, transforma-se foge completamente ao ponto de vista dialético. Quem vê imobilidade no mundo natural não enxerga senão a espuma sobre um profundo oceano de movimento e transformação. Não podemos cair na armadilha de essencializar a doença como algo a-histórico e a-geográfico, descolado do mundo social e natural concreto. A febre amarela, assim como todas as relações e estruturas biofísicas por trás dela, não poderiam ser as mesmas em 1850 e 1870; elas haviam mudado juntamente com as relações sociais e as visões de mundo. Já mencionamos a questão da mudança no padrão de incidência da febre pelo fato de que, com o tempo, todos os nascidos no Brasil (em adição aos adventícios africanos) adquiriam maior resistência a um ataque fatal; sendo o período em tela de uma geração, é de se supor que, em 1870, já houvesse muito mais brancos resistentes. Outra transformação importante sobre a qual podemos especular é a difusão do ciclo silvestre do vírus por toda a franja florestal da província fluminense bem como a difusão do ciclo urbano por toda a costa e mesmo pelas cidades mais interioranas do território brasileiro.

Alguns autores procuram desconstruir o discurso hegemônico da época - 
que associava febre amarela e habitações coletivas - apelando, mesmo que implicitamente, a uma suposta indiferenciação espacial do complexo patogênico da doença. "Mosquitos há em toda parte", escreve Barbosa (1992, p.324) citando uma peça de Artur Azevedo. Mosquitos certamente havia em todos os cantos do Rio, mas certamente não todos os mosquitos em toda parte. Os $A$. aegypit adultos, em particular, possuem um raio de ação muito pequeno, mantendo-se, em geral, por toda a vida, a uma distância máxima de $200 \mathrm{~m}$ dos locais de onde eclodem de seus ovos (FIGUEIREDO e FONSECA, 2005). ${ }^{10}$ Isto significa que podem ser criadas áreas endêmicas de reduzido tamanho dentro de uma cidade, como de fato parece ter acontecido com o centro do Rio de Janeiro. Os "cortiços" eram, realmente, ambientes mais do que apropriados à reprodução do mosquito:

Este tipo de habitação caracterizava-se pela disposição de uma multiplicidade de quartinhos em volta de uma área aberta que, entretanto, era mantida quase que constantemente encharcada, já que era ali que as lavadeiras, que constituíam um percentual importante da população, faziam seu trabalho. Não é de espantar, também, que era nesses locais que o Aedes Aegypti mais deixava a sua terrível marca (ABREU, 1992, p.68).

Deixemos bem claro. Não está em disputa que "o controle dos cortiços e estalagens possuía conotações nem sempre explícitas no discurso das autoridades" (BARBOSA, 1992, p.324). Contudo, não podemos perder de vista as dinâmicas materiais que condicionavam a viabilidade dos projetos ideológicos e discursivos. O que queremos pontuar é que havia, sim, razões ecológicas concretas para que a febre amarela assolasse os cortiços da área central mais do que outras regiões da cidade. Um conhecimento mais completo dos processos de mudança social requer que entrelacemos os conceitos de poder e natureza (STEINBERG, 2002). Se o exercício do poder não carece de justificativa - pois é inerente a qualquer comunidade política -, ele sempre demanda legitimidade (ARENDT apud SOUZA, 1995). Essa legitimidade é freqüentemente produzida por intermédio da apropriação discursiva $\mathrm{e}$ ideológica de relações e processos não-humanos. É muito provável que a

10 Evidentemente, essa característica ecológica dos mosquitos varia muito. Uma das espécies transmissoras da malária (Anopheles darlingi), por exemplo, pode se movimentar num raio de até $100 \mathrm{~km}$. 
cruzada contra os cortiços não tivesse ganhado tanto momentum político se não houvesse a febre amarela e a malária provendo fenômenos que podiam ser facilmente lidos pelas pessoas como uma clara comprovação dos reclames higienistas. A construção ideológica precisa sempre se apoiar sobre uma gama razoável de dados sensíveis, ainda mais em uma sociedade pré-industrial onde a informação carece das quase infinitas mediações técnicas de nosso período atual. A coincidência espacial entre cortiços e febre amarela era inegavelmente forte, embora estivesse longe de ser absoluta. Na epidemia de 1891, por exemplo, as freguesias mais atingidas foram exatamente aquelas onde era maior a densidade de habitações coletivas: bem à frente das demais estavam as de São José e Santana, com 15,5\% e 9,2\% do número total de casos de febre, respectivamente. ${ }^{11}$ Juntas, essas duas freguesias continham mais de 40\% dos cortiços da cidade, em 1886 (GOMES, 2008). Os (pobres) cariocas pobres viam-se, assim, enredados em uma dinâmica perversa ainda bastante presente em nossos dias. Economicamente constrangidos a morar em amontoados nas áreas topograficamente mais baixas, eles acabavam contribuindo passivamente para a criação de outros problemas ambientais. Como foco de epidemias, eles forneciam ampla base empírica para as construções ideológicas que os apontavam como culpados não somente por suas próprias condições de vida, mas por toda sorte de mal que houvesse na cidade.

CAVALCANTE (1985), MARQUES (1995) e o já citado CHALHOUB (1996), dentre outros autores, identificam uma "ideologia da higiene" como parte do processo mais amplo de transição das práticas senhoriais às práticas liberais de dominação social, na segunda metade do século XIX. Não bastava controlar o novo trabalhador livre no espaço público através de leis contra 0 ócio e outras do tipo; era preciso controlá-lo também no espaço e nas práticas domésticas. Conjugando as condições ambientais desfavoráveis (acumulação de "águas servidas" e de excrementos humanos e animais) a qualidades morais automaticamente atribuídas aos pobres (indolência, promiscuidade,

\footnotetext{
${ }^{11}$ A freguesia de São Cristóvão registrou o exorbitante número de 1.745 casos ( $39,2 \%$ do total), mas isso se deve ao fato de que, nesta área, estava localizado o Hospital São Sebastião (BENCHIMOL, 1990, p.179).
} 
bandidagem), a ideologia da higiene estabelecia os cortiços como as fontes por excelência dos temidos miasmas, e os seus moradores como uma "classe perigosa". A atuação intrusiva do poder público nas habitações coletivas isolando pessoas, queimando roupas e utensílios do doente, desinfetando o lugar com substâncias químicas, desautorizando práticas tradicionais de cura era uma ofensiva no sentido de desarticular a cultura popular da classe trabalhadora e torná-la dependente do conhecimento, dos valores e dos instrumentos do Estado e da elite.

Os conceitos propalados pelo higienismo fincaram profundas raízes no imaginário coletivo. Essa ideologia "infiltrou-se no senso comum das camadas dominantes e das camadas médias, culturalmente subalternas, que nos anos setenta já constituíam uma influente 'opinião pública'” (BENCHIMOL, 1990, p.118). O segredo do sucesso dessa construção hegemônica - como de resto de todas as construções hegemônicas - era a sua aparente neutralidade, sua suposta isenção sociopolítica em busca de valores tidos como intrinsecamente verdadeiros: "progresso" e "civilização". Tratava-se de "fazer política deslegitimando o lugar da política na história" (CHALHOUB, 1996, p.35), mas também no espaço. Desde meados do século, eles defendiam que, para o bem coletivo, o centro da cidade deveria ser evadido de "usos sujos" como matadouros e cemitérios, mas agora eles ampliavam o espectro de evasões para abarcar as aglomerações de gente suja e perigosa. Em sua luta por reconhecimento social e poder na condução das políticas urbanas, os higienistas conseguiram sensibilizar os setores empresariais e financeiros, que então perceberam a oportunidade de investimentos e lucros. As estalagens e cortiços ocupavam muitos terrenos cujo valor de troca vinha aumentando bastante com o adensamento urbano e a conseqüente escassez de sítios próximos ao porto e ao centro de negócios da cidade. A ciência da higiene fornecia excelentes elementos retórico-ideológicos que legitimavam a extirpação desses "usos sujos" e do pequeno capital rentista que lhe estava associado, abrindo caminho para a entrada do capital financeiro na produção do espaço urbano carioca. É neste sentido que Chalhoub (1996, p. 56) fala em uma "aliança entre a Ciência e o Capital, aliança que seria essencial às 
transformações urbanas 'radicais' [...] do início do século XX no Rio" (ele se refere à reforma conduzida por Pereira Passos).

Todos os organismos vivos são sustentados pelo movimento da água. Dos sistemas terrestres para os tecidos vivos, do oceano para a atmosfera - e destes de volta para aqueles, num ciclo interminável. A atividade humana, como atividade de um organismo vivo - embora um organismo diferenciado, conscientemente perceptivo -, envolve sempre a mobilização, direta ou indireta, de água. Os dramas humanos, portanto, não poderiam ser outra coisa que não dramas da água. Ao "seguir o fio de Ariadne através da água" (SWYNGEDOUW, 2001, p.85), podemos narrar muitas histórias que, em seu entrelaçamento, nos dão um quadro de determinado espaço humano. As histórias da geopolítica urbana dos chafarizes, das enchentes e das secas, dos aterros, da febre amarela, dos cortiços, do desflorestamento e do reflorestamento, do abastecimento madeireiro, do comércio de escravos, da tecnocracia da higiene - às quais, evidentemente, poderiam se juntar muitas outras - fornecem um relato multidimensional, mas estruturado, das transformações vividas pela cidade do Rio, ao longo do século XIX. Embora diferentes no que tange aos protagonistas humanos específicos e seus respectivos "tempos", objetivos e estratégias, todas essas histórias condensam-se ao redor desse núcleo de relações que é a água.

A água é sempre, e simultaneamente, universal e particular. Ainda que a forma de seus fluxos seja histórica e geograficamente contingente, ela continua sendo uma única substância (TVEDT, 2010). Essa dualidade intrínseca faz dela uma espécie de "nó diegético" a partir do qual se irradiam e para o qual convergem inúmeras histórias humanas. Nesse processo de conhecimento, "tudo se passa como se a generosidade da água não cessasse de escapar ao entendimento, de ultrapassar os limites de cada questão construída, de sugerir novas frentes de investigação" (SANT'ANNA, 2007, p.295). Mas, por outro lado, é exatamente esse escorregar incessante o fundamento que dá coerência 
ao quadro total obtido. O fato de a água ser una, mas, ao mesmo tempo, múltipla em suas relações com os humanos - sua capacidade de saciar a sede dos humanos, mas também de afogá-los e destruir seu ambiente construído, de servir à reprodução de mosquitos, sua afinidade com as árvores da floresta, sua combinação com a força da gravidade, etc. - enseja uma rede narrativa e, portanto, uma forma de ordenamento e compreensão do real. Trata-se de uma trama, um corte fenomênico em que há uma ordem inextricavelmente temporal e espacial; e por isso podemos falar, indiferentemente, em narrativa geográfica ou descrição histórica. ${ }^{12}$

Essa abordagem permite superar as divisões rígidas entre Sociedade e Natureza em favor de "uma leitura dinâmica e integrativa, fundada na observação do mundo" (PÁDUA, 2010, p. 97). A trama da água reúne o Social e o Natural, mas não como as "abstrações singulares" de que fala Williams (1980). Neste ponto, é preciso lembrar que, na indicação do campo de preocupações, bem como no discurso ontológico que o funda, a linguagem dualista é inevitável. Ao nível historiográfico, contudo, o que se apresenta não é o "homem genérico desincorporado da geografia cultural ortodoxa, e sim indivíduos e grupos de indivíduos em relação a específicas paisagens sóciohistóricas" (DUNCAN, 2002[1980], p.27). É preciso substituir o fetichismo ontológico pelas múltiplas e caleidoscópicas distinções concretas que se estruturam na tensão entre uma vontade técnica e semântica de controlar a espontaneidade e a auto-organização do ser natural, que é ser-em-si, indiferente a qualquer teleologia. ${ }^{13}$ Não se trata simplesmente de "decompor" Sociedade e Natureza (posto que não são coisas nem lugares), e sim, num sentido epistemológico e metodológico mais profundo, fazê-los surgir contextualmente através da narração dos encontros e desencontros dos humanos com as relações, estruturas e processos da physis - começando, evidentemente, pelos próprios corpos humanos. Organizadas a partir do nó hídrico, essas narrativas ganham um sentido mais abrangente, combinando de maneira complexa e contraditória o não-humano e o humano, o orgânico e o

\footnotetext{
${ }^{12}$ Nossa noção de trama é inspirada nas discussões de Veyne (1982) e Gomes (2009), o primeiro pela vertente da história e o segundo, pela vertente da geografia.

${ }^{13}$ A natureza "é cega, não tem futuro" (SANTOS, 1996, p. 67).
} 
organizacional, o material e o representacional, o local e o global. Deste modo, transferimos o foco da investigação das relações externas entre domínios puros e coisificados para as tramas através das quais Sociedade e Natureza hidridizam-se, ou seja, realizam-se como acontecimentos históricos concretos.

\section{REFERÊNCIAS ARQUIVÍSTICAS}

ANRJ - ARQUIVO NACIONAL DO RIO DE JANEIRO. Fundo Vice-Reinado, caixa 498, pacote 01 . volume 1.

Fundo Polícia da Corte, códice 323, volumes 1 e 4, e códice 327,

IHGB - INSTITUTO HISTÓRICO E GEOGRÁFICO BRASILEIRO. MP 1, Gav. 3 , n. 12.

\section{REFERÊNCIAS BIBLIOGRÁFICAS}

ABREU, M.A. A cidade, a montanha e a floresta. In: (org.) Natureza e sociedade no Rio de Janeiro. Rio de Janeiro: Prefeitura da Cidade do Rio de Janeiro, 1992, pp. 54-103.

. A cidade e os temporais: uma relação antiga. In: Rosa, L.P.; Lacerda, W.A. (coord.) Tormentas cariocas. Rio de Janeiro: COPPE/UFRJ, 1997, pp. 1520.

- Evolução urbana do Rio de Janeiro. 4⿳亠丷a ed. Rio de Janeiro: Instituto Municipal de Urbanismo Pereira Passos, 2006.

BARBOSA, J.L. Olhos de ver, olhos de ouvir: os ambientes 'malsãos' da capital da República. In: Abreu, op. cit., 1992, pp .317-29.

BARRETT, A.D.T.; HIGGS, S. Yellow fever: A disease that has yet to be conquered. Annual Review of Entomology vol.52, 2007, pp. 209-29.

BENCHIMOL, J.L. Pereira Passos: um Haussmann tropical. Rio de Janeiro: Prefeitura da Cidade do Rio de Janeiro, 1990.

- História da febre amarela no Brasil. História, Ciências, Saúde Manguinhos, vol.1, n.1, 1994, pp. 121-24.

BRANDÃO, A.M.P. As alterações climáticas na área metropolitana do Rio de 
Janeiro: uma provável influência do crescimento urbano. In: Abreu, op. cit., 1992, pp. 143-200.

BROWN, L.V. Internal commerce in a colonial economy: Rio de Janeiro and it's hinterland, 1790-1822. Tese de doutoramento. Washington, D.C.: University of Virginia, 1986.

CAVALCANTE, B.O. Beleza, limpeza, ordem e progresso: a questão da higiene na cidade do Rio de Janeiro, final do século XIX. Revista Rio de Janeiro vol.1, n.1, 1985, pp. 95-103.

CHALHOUB, S. Cidade febril: cortiços e epidemias na Corte imperial. São Paulo: Cia. das Letras, 1996.

CRONON, W. A place for stories: Nature, history, and narrative. Journal of American History vol.78, n.4, 1992, pp. 1347-76.

DAMASCENO, A.N. Os miasmas, os médicos e a relação homem-natureza na cidade do Rio de Janeiro no século XIX. Dissertação (Mestrado em Geografia). Rio de Janeiro: PPGG/UFRJ, 1993.

DEAN, W. A ferro e fogo: a história e a devastação da Mata Atlântica brasileira. São Paulo: Cia. das Letras, 1996.

DRUMMOND, J.A. Ciência social e ciência sócio-ambiental. Revista de Sociologia e Política n.20, 2003, pp. 157-159.

DUNCAN, J.S. O supraorgânico na geografia cultural americana. Espaço e Cultura n.13, 2002[1980], pp. 7-33.

FIGUEIREDO, L.T.M.; FONSECA, B.A.L. Febre amarela. In: Veronesi, R.; Focaccia, R. Tratado de Infectologia. 3aㅡ ed. São Paulo: Atheneu, 2005, pp. 389397.

FOSTER, J.B. A ecologia de Marx: materialismo e natureza. Rio de Janeiro: Civilização Brasileira, 2005.

FRAGOSO, J.; FLORENTINO, M. O arcaísmo como projeto: mercado atlântico, sociedade agrária e elite mercantil em uma economia colonial tardia. 4⿳亠丷a ed. Rio de Janeiro: Civilização Brasileira, 2001.

FRANÇA, J.M.C. Visões do Rio de Janeiro colonial: antologia de textos, 1531 1800. Rio de Janeiro: José Olympio/Eduerj, 1999. 
FRIAS, R.C. A expansão do sistema de abastecimento d'água da cidade do Rio de Janeiro (1723-1846). III Simpósio Iberoamericano de História da Cartografia. São Paulo: Universidade de São Paulo, 2010. Disponível em http://3siahc.files.wordpress.com/2010/05/artigo-3-siahc-1.pdf.

GOMES, M.V.S. Onde moravam os pobres no Rio Antigo? Um estudo sobre as habitações coletivas no Rio oitocentista. Monografia (Conclusão de Curso de Graduação em Geografia). Rio de Janeiro: IGEO/UFRJ, 2008.

GOMES, P.C.C. Um lugar para a geografia: contra o simples, o banal e o doutrinário. In: Mendonça, F.A.; Lowen-Sahr, C.L.; Silva, M. (orgs.) Espaço e tempo: complexidade e desafios do pensar e do fazer geográfico. Curitiba: ADEMADAN, 2009, pp. 13-30.

HAESBAERT, R. O mito da desterritorialização. Do fim dos territórios à multiterritorialidade. Rio de Janeiro: Bertrand Brasil, 2007.

HEYNEMANN, C. Floresta da Tijuca: natureza e civilização. Rio de Janeiro: Secretaria Municipal de Cultura, 1995.

HERVÉ, J-P.; DEGALLIER, N.; SÁ FILHO, G.C.; ROSA, A.P.A.T. Ecologia da febre amarela silvestre no Brasil. Revista da Fundação SESP vol.31, n.2, 1986, pp. 131-134.

IMENES, J.J.S.; MORAES, J.M.P.; GALVÃO FILHO, R.A. Abastecimento d'água à cidade do Rio de Janeiro. Memória sobre este assumpto e proposta submetida à decisão do corpo legislativo em Janeiro de 1873. Typografia Universal de Laemmert, 1873 [disponível no Instituto Histórico e Geográfico Brasileiro, 13, 5, 23].

JARDIM, J.R.M.; BARROS, L.F.M. Projeto de abastecimento d'água para a cidade do Rio de Janeiro. Rio de Janeiro: Typografia de J. Paulo Hildebrandt, 1874 [disponível no Instituto Histórico e Geográfico Brasileiro, 200, 8, 1, n.7].

KARASCH, M.C. A vida dos escravos no Rio de Janeiro (1808-1850). São Paulo: Cia. das Letras, 2000[1987].

LUCCOCK, J. Notas sobre o Rio de Janeiro e partes meridionais do Brasil. Belo Horizonte: Itatiaia, 1975[1820].

MARQUES, E.C. Da higiene à construção da cidade: o Estado e o saneamento no Rio de Janeiro. História, Ciências, Saúde - Manguinhos vol.2, n.2, 1995, pp. 51-67. 
MARTINS, L.L.; ABREU, M.A. Paradoxes of modernity: imperial Rio de Janeiro, 1808-1821. Geoforum vol.32, 2001, pp. 533-550.

McNEILL, J.R. Ecologia, epidemias e impérios: mudanças no ambiente e a geopolítica da América tropical, 1600-1825. In: História e meio-ambiente: o impacto da expansão européia. Funchal: Centro de Estudos de História do Atlântico/Secretaria Regional do Turismo e Cultura, 1999, pp. 301-311.

MILLER, S.W. Stilt-root subsistence: Colonial mangroves and Brazil's landless poor. Hispanic American Historical Review, vol.83, n.2, 2003, pp. 223-253.

MORALES DE LOS RIOS FILHO, A. O Rio de Janeiro Imperial. $2^{\underline{a}}$ ed. Rio de Janeiro: Topbooks, 2000[1946].

PÁDUA, J.A. Um sopro de destruição: pensamento político e crítica ambiental no Brasil escravista (1786-1888). 2ª ed. Rio de Janeiro: Jorge Zahar Ed., 2004.

As bases teóricas da história ambiental. Estudos Avançados vol.24, n.68, 2010, pp. 81-101.

PLUMWOOD, V. The concept of a cultural landscape: Nature, culture, and agency in the land. Ethics and the Environment vol.11 (2), 2006, pp. 115-150.

SANT'ANNA, D.B. Cidade das águas: usos de rios, córregos, bicas e chafarizes em São Paulo (1822-1901). São Paulo: Ed. Senac, 2007.

SANTOS, M. A natureza do espaço. Técnica e tempo, razão e emoção. São Paulo: Hucitec, 1996.

SILVA, R.M. A luta pela água. In: Silva, Fernando N. da (dir.) O Rio de Janeiro em seus quatrocentos anos: formação e desenvolvimento da cidade. Rio de Janeiro: Record, 1965, pp. 311-337.

SOUZA, M.L. O território: sobre espaço e poder, autonomia e desenvolvimento. In: Castro, Iná E.; Gomes, Paulo César da C.; Corrêa, Roberto L. (orgs.). Geografia: conceitos e temas. Rio de Janeiro: Bertrand Brasil, 1995, pp. 77116.

STEINBERG, T. Down to Earth: Nature, agency, and power in History. American Historical Review vol.107, n.3, 2002, pp. 798-820.

STROUD, E. Does nature always matter? Following dirt through History. History and Theory vol.42, n.4, 2003, pp. 75-81. 
SWYNGEDOUW, E. A cidade como um híbrido: natureza, sociedade e 'urbanização-cyborg'. In: Acselrad, H. (org.). A duração das cidades: sustentabilidade e risco nas políticas urbanas. Rio de Janeiro: DP\&A, 2001, pp. 83-104.

TAUNAY, C.A. Manual do agricultor brasileiro. São Paulo: Cia. das Letras, 2001[1839].

TVEDT, T. 'Water systems', environmental history and the deconstruction of nature. Environment and History vol.16, 2010, pp. 143-66.

VEYNE, P. Como se escreve a história; Foucault revoluciona a história. Brasília-DF: Ed. UnB, 1982.

VIANA, P.F. Abreviada demonstração dos trabalhos da Polícia em todo o tempo que a serviu o Desembargador do Paço Paulo Fernandes Viana. Revista do Instituto Histórico e Geográfico Brasileiro, tomo 35, 1892, pp. 373-380.

WATTS, S. Yellow fever immunities in West Africa and the Americas in the age of slavery and beyond: A reappraisal. Journal of Social History vol.34, n.4, 2001, pp. 955-967.

WHITE, R. The nationalization of nature. Journal of American History vol.86, n.3, 1999, pp. 976-986.

WILLIAMS, R. Ideas of nature. In: Problems in materialism and culture: Selected essays. London: Verso, 1980, pp. 67-85.

WORSTER, D. Para fazer história ambiental. Estudos Históricos vol.4, n.8, 1991, pp. 198-215. 


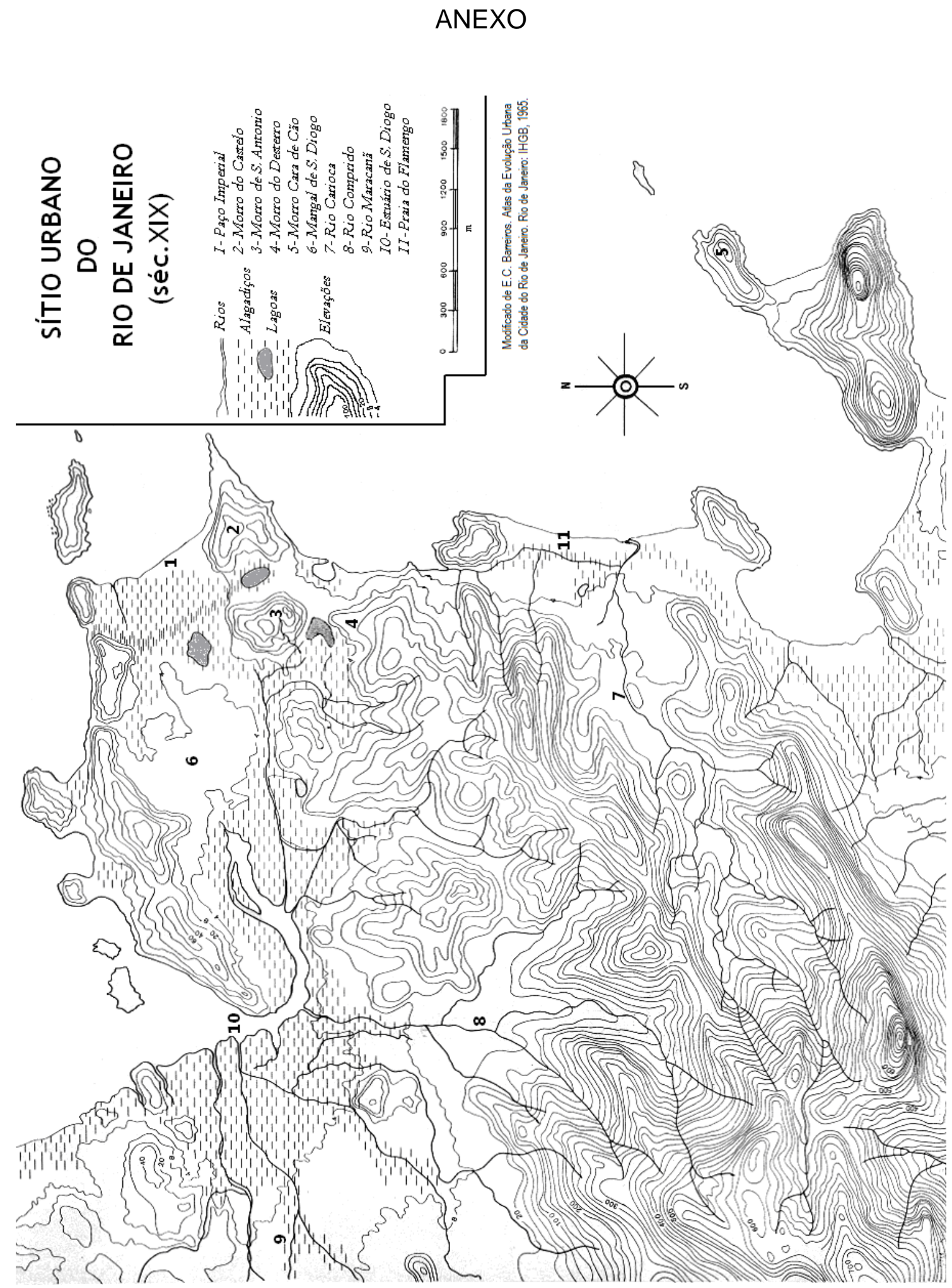

